REVIEW

\title{
Chronic non-malignant musculoskeletal pain in older adults: clinical issues and opioid intervention
}

\author{
V K Podichetty, D J Mazanec, R S Biscup
}

Postgrad Med J 2003;79:627-633

Musculoskeletal pain is common, frequently underreported, and inadequately treated in the older adult. The objective of this article is to review the management of musculoskeletal pain syndromes in older adults emphasising the potential role of opioid agents in carefully selected patients. Systematic analysis of the relevant literature was done. Even in cognitively impaired patients, assessment of musculoskeletal pain is mandatory. An algorithm for musculoskeletal pain is presented emphasising a stepwise pharmacological approach in combination with an array of non-pharmacological therapies. Comorbid conditions may limit therapeutic choices, particularly in the elderly. Repeated assessment of pain levels as well as functional status is critical for optimal pain management.

See end of article for authors' affiliations

Correspondence to: Dr Vinod K Podichetty, Director, Research Studies and Education, Cleveland Clinic Florida Spine Institute, 2950 Cleveland Clinic Blvd, Weston, FL 33331 USA; podichv@ccf.org

Submitted 30 January 2003 Accepted 12 June 2003

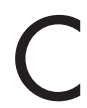
hanges in the demographic characteristics of the world population represent a critical challenge to clinicians. The number of adults aged 65 and older continues to grow at an unprecedented rate. The definition of the elderly, according to the United Nations, are those 65 years and more, which constitute the elderly (older persons) and those 80 years or more making up the oldest old. ${ }^{1}$ In the United States individuals who had reached their 65th birthday accounted for only $4 \%$ of the total population in 1900, but currently number 35 million persons, approximately $13 \%$ of the population. ${ }^{2}$ Although the number of those aged 85 or older in 1990 accounted for little more than $1 \%$ of the population, their representation within the general populace is projected to quadruple by $2050 .^{24}$

The aging of the world's population exhibits similar trends. According to the United Nations, ${ }^{5}$ the number of people worldwide aged 60 years or older will increase from one in 10 currently, to one in five by 2050 . In some developed countries this proportion will increase from the projected one in five to one in two by the year 2050. The population aged 80 years or older is also projected to increase from $11 \%$ of those older than 60 years now to $19 \%$ by 2050 . The number of centenarians is expected to increase 15 -fold to 2.2 million. The rate of aging of the population is greatest in developing countries, a growing challenge for nations with few health care resources. By 2050, the ratio of people 65 years or older to those aged 15-64 years will double in developed nations and triple in developing nations. ${ }^{5}$ In an aging population, chronic disabling conditions are most common. ${ }^{6-8}$ Empirical evidence of the association between the presence of musculoskeletal pain and physical disability has been reported in the older adult. ${ }^{9}$

Despite the ready availability of effective pharmacological and non-pharmacological treatments, inadequate management of pain, particularly in the elderly, is well documented in the United States. ${ }^{10-12}$ The most common aetiology of chronic non-malignant pain in older persons is musculoskeletal including arthritis and myofascial pain syndromes. According to the National Council on Aging, the major sources of pain identified in nursing home patients included arthritis $(24 \%)$ and previous fractures $(14 \%) .^{13}$ Similarly, another study concluded the most common causes of pain in nursing home patients to be arthritis $(70 \%)$ and previous fractures (13\%)..$^{14}$ For example the frequency of symptomatic osteoarthritis of the hip and knee is $9 \%$ in persons aged 30 and over. ${ }^{15}$ Radiographically, knee osteoarthritis is nearly twice more common in women and increases with increasing age, reaching a prevalence of $19.5 \%$ to $25 \%$ in women by 65 years of age. ${ }^{16-18}$ Approximately one third of the patients with radiographic knee osteoarthritis experience symptoms. ${ }^{16}{ }^{17}$ Because of the magnitude of the problem, we aim to review the management of musculoskeletal pain syndromes in older adults and emphasise the potential role of opioid agents in carefully selected patients through this article.

\section{MUSCULOSKELETAL PAIN IN THE OLDER ADULT}

The increasing role of surgical treatment of musculoskeletal pain in the older adult underlines the magnitude of the problem. In the Medicare population in the United States for example, rates of total joint replacement surgery for patients with severe hip or knee osteoarthritis more than doubled between 1988 and 1997. Over the same time period, rates of spine surgery in Medicare patients increased by $57 \%{ }^{19}$

Other non-rheumatic disorders more common in older patients may also present with musculoskeletal pain. For example symptoms associated with Parkinson's disease include muscle

Abbreviations: COX-2, cyclo-oxygenase-2; NSAID, non-steroidal anti-inflammatory drug; TCA, tricyclic antidepressant; TENS, transcutaneous electrical nerve stimulation 
cramps or tightness in the neck, back, and legs; a dull pain in the head and neck; painful dystonias especially in the feet; and neuropathic pain consisting of burning pain, tingling, or numbness. ${ }^{20}$ Careful evaluation of the elderly with musculoskeletal pain symptoms for such non-rheumatic disorders is mandatory. Not only is musculoskeletal pain a common problem in the elderly, it commonly leads to a decrease in functional ability and quality of life. ${ }^{21}$ Chronic pain is a complex phenomenon and requires a multifaceted approach incorporating non-pharmacological and pharmacological modalities. For carefully selected patients, opioids may provide excellent analgesia with a favourable risk: benefit ratio.

\section{UNIQUE ISSUES IN PAIN MANAGEMENT IN THE OLDER ADULT}

Although elders suffer chronic pain more frequently than do other populations, ${ }^{1322} 23$ their pain is often under-reported and under-treated. ${ }^{13} 2425$

Reasons for under-reporting are the beliefs and expectations about pain as a normal part of aging or concern, poor health education among the elderly, misinterpretation of symptoms because of concomitant disease, and communication problems. The discrepancy between the high prevalence of pain in the elderly and the limited attention paid to this group in the research literature and in medical and nursing texts has also been noted. ${ }^{26}$ Of all reports about pain published annually, fewer than $1 \%$ focus on pain experience or syndromes in the elderly. ${ }^{27}$ The consequences of poorly managed pain, particularly in the elderly, may include depression, ${ }^{24} 2528-33$ social isolation, ${ }^{24} 25$ sleep disturbance, ${ }^{2425}$ decreased ambulation, ${ }^{24}{ }^{25}$ and increased healthcare utilisation and cost. ${ }^{25}$

Comorbid medical conditions are typically much more common in an elderly population. ${ }^{28}{ }^{34}$ Many patients over 65 have multiple non-rheumatic disease conditions such as cardiovascular disease, diabetes, hypertension, and renal disease that functionally limit normal activity. These medical problems significantly complicate treatment of musculoskeletal symptoms. Memory and cognitive impairment add to this problem. Cognitive impairment, delirium (common among the acutely ill elderly), and dementia (which occurs in as many as $50 \%$ of the institutionalised elderly) pose serious barriers to pain assessment. ${ }^{35}$ Patients with cognitive impairment have been the subjects of two significant studies. ${ }^{14}{ }^{36}$ Parmelee et al concluded that in patients with mild to moderate cognitive impairment, complaints of pain were no less valid than in patients with normal cognitive function. ${ }^{36}$ In a separate study, the investigators found that at least $80 \%$ of patients could respond to at least one of the scales and give meaningful and probably reliable information about their pain. ${ }^{14}$

The initial assessment of the older person with musculoskeletal pain should address at least the following primary objectives: distinguish patients with common musculoskeletal causes of pain from those with serious visceral or nonrheumatic spinal pain; identify significant comorbid conditions that may influence the treatment or may even present as musculoskeletal pain; and recognise significant complicating psychosocial issues that may impact on the management of the patient's pain. ${ }^{28}$

\section{PAIN MANAGEMENT IN THE OLDER PATIENT}

The American Geriatrics Society disseminated a clinical practice guideline for the management of chronic pain in older populations in $1998 .{ }^{25}$ Since then, important advances in pharmacology and strategies for the assessment and management of pain in the elderly have emerged..$^{37} 38$ Unfortunately, pain management strategies for older patients have not been systematically evaluated, and most approaches have been extrapolated from clinical experience with younger patients and patients with cancer pain. Both non-pharmacological and pharmacological modalities should be considered with treatment individualised as much as possible.

A proposed pain treatment algorithm for chronic nonmalignant musculoskeletal pain is shown in fig 1 .

\section{NON-PHARMACOLOGICAL STRATEGIES}

Non-pharmacological approaches used alone or in combination with appropriate pharmacological strategies should be an integral part of care plans for most chronic pain patients. ${ }^{39}$ These approaches may augment the efficacy of medications, but typically have fewer adverse effects. Non-pharmacological therapies and interventions include physical therapy, occupational therapy, exercise modalities, transcutaneous electrical nerve stimulation (TENS), education, acupuncture, and social support.

Evidence supporting the effectiveness of physical therapy is well documented, and active exercises, conditioning, and incorporating weight training into an exercise programme is commonly prescribed for patients with chronic musculoskeletal pain. ${ }^{40}{ }^{41}$ Although comorbid medical conditions and the general frailty of elderly patients often raise concerns about safety of an exercise oriented approach, published trials of non-medicinal and non-invasive therapies for hip and knee osteoarthritis have shown beneficial effects in older persons participating in exercises. ${ }^{42}{ }^{43}$ Occupational therapy interventions that focus on everyday practices of the older adult can make a significant difference to a patient's independence and reduce hazards. Minor modifications should be made, if appropriate, like installation of handrails, raised seats, and improved lighting within the home.

Controlled trials ${ }^{44}$ and more recent meta-analysis ${ }^{45}{ }^{46}$ have concluded that TENS is not effective in the treatment of chronic low back pain. Despite this evidence, TENS is widely used to treat chronic musculoskeletal pain in elderly patients. So called passive modalities such as massage, ultrasound, heat, or ice may provide temporary symptomatic relief with the advantage of minimising transport of the older patient and low cost treatment. A recent assessment of nutraceuticals (foods or naturally occurring food supplements thought to have a beneficial effect on human health such as glucosamine) as therapeutic agents in osteoarthritis has suggested a beneficial effect on chronic musculoskeletal symptoms ranging from moderate to large. ${ }^{47} 48$

Additional research has shown that simply providing a supportive environment helps to control pain. ${ }^{49}$ Providing patients and families accurate and understandable information about pain, pain assessment, and the use of drugs and other methods of pain relief, as well as emphasising that almost all pain can be effectively managed, improves outcome. Patient education should also address major barriers to effective pain management, namely, patients' reluctance to talk about their pain with their care providers, their fears about becoming addicted to opioids, and that the pain cannot be effectively controlled without unacceptable consequences. Other misconceptions, such as the thought that pain medication should be saved for when pain is severe or else it might not be effective, should be addressed. ${ }^{50}$

Patients who receive medication related education have a higher rate of compliance with analgesic prescriptions, fewer concerns about taking opioid analgesics, and lower pain levels than do patients not given such information. ${ }^{51}$

\section{PHARMACOLOGICAL INTERVENTION}

Available analgesics include non-opioids such as acetaminophen (paracetamol in the UK) ${ }^{52}$ non-steroidal anti-inflammatory drugs (NSAIDs), ${ }^{53}$ cyclo-oxygenase-2 (COX-2) 


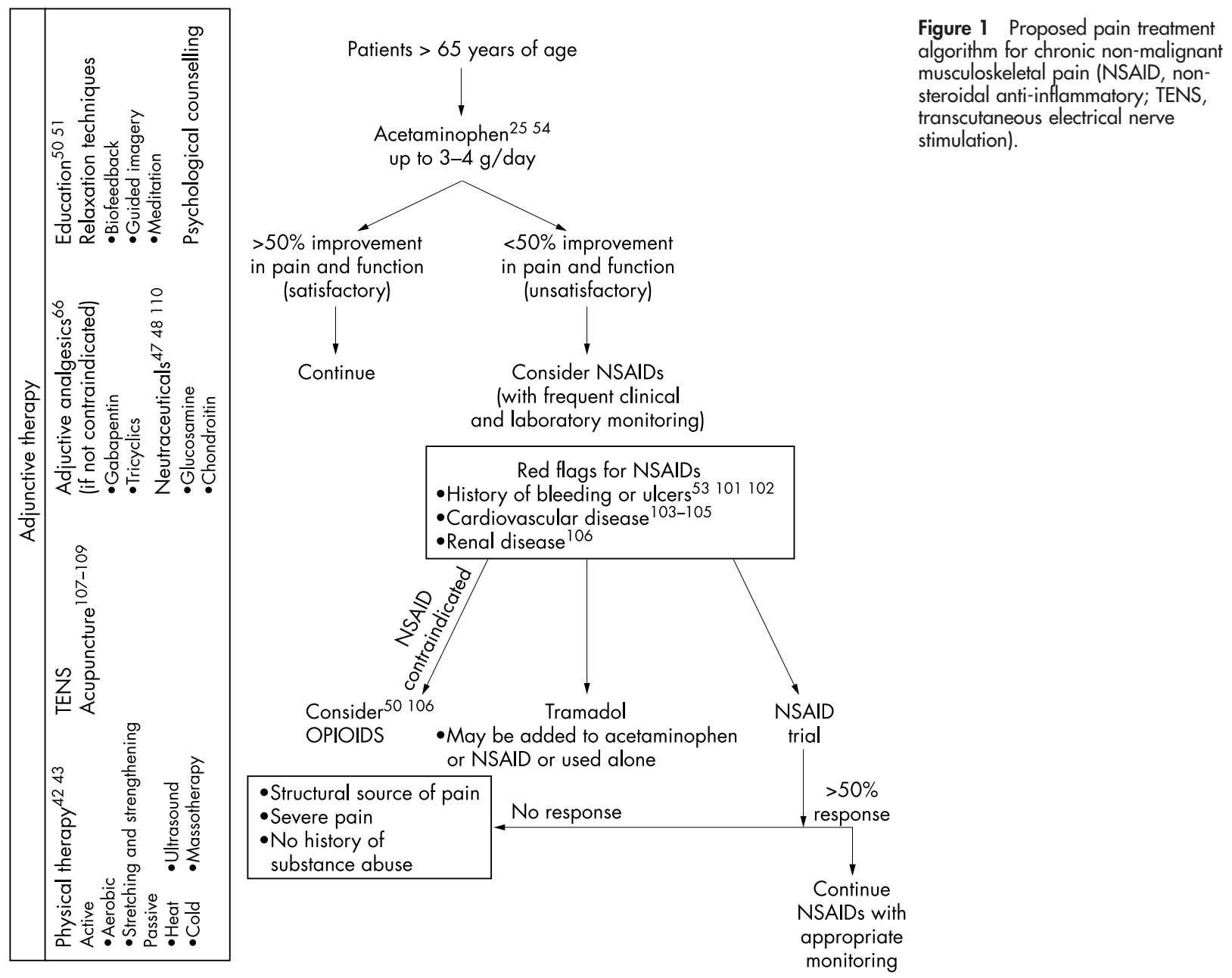

specific NSAIDs; weak opioids such as codeine and tramadol, ${ }^{54}$ and opioids such as oxycodone and morphine. As noted in the American Geriatrics Society 2002 guidelines, the higher risk of adverse effects of some effective analgesics limits their use in the older patient. ${ }^{37}$ The American Geriatrics Society clinical practice guideline $2002^{37}$ and the American College of Rheumatology $y^{52} 56$ both recommend acetaminophen as the first line agent in the treatment of mild to moderate pain of musculoskeletal origin.

Studies comparing acetaminophen and ibuprofen or naproxen in osteoarthritis of the knee have demonstrated comparable efficacy in outcomes. NSAID toxicity both renal and gastrointestinal is increased in older patients. ${ }^{56} 57$ The risk of serious complications associated with NSAIDs increases by $4 \%$ for each one year increase in age after 65 years. ${ }^{57}$ Elderly patients with reduced renal perfusion or cardiovascular disease are more dependent on renal prostaglandin synthesis to maintain renal blood flow. NSAID therapy may precipitate renal failure and increase the risk of hospitalisation for congestive heart failure in patients with cardiovascular disease by 10-fold. COX-2 selective NSAIDs offer improved gastrointestinal tolerance but pose similar risk to renal function. The elderly are more sensitive to the side effects of drugs such as the NSAIDs described and this can be compounded by other drugs, for example, steroids. This is an important consideration in elderly patients with concomitant disease who may be on numerous drugs and may be an influencing factor in prescribing analgesics.

Tramadol, with its indication for moderate to moderately severe pain, can be considered a suitable choice for osteoarthritis pain unrelieved by acetaminophen. ${ }^{58}$ Tramadol is a centrally acting analgesic with weak affinity for $\mu$-opioid receptors as an agonist, which possibly allows its efficacy to stretch over a wider range of painful pathologies than the other opioids..$^{50}$ Owing to its pharmacological properties, it is more appropriate for patients suffering from gastrointestinal (constipation) and renal problems, ${ }^{61}$ combined with low dependence potential, ${ }^{62}$ which proves to be a significant advantage over the other agents, especially in the elderly.

Tricyclic antidepressants (TCAs) have long been used for the treatment of chronic neuropathic pain and strong evidence from systematic reviews of randomised trials showing their effectiveness has been reported. ${ }^{63-65}$ There may be a role for TCAs among selected elderly, who are likely to suffer from chronic painful conditions. ${ }^{66}$ The analgesic effects of TCAs appear to be independent of any antidepressant effect, as TCAs have been shown to be effective in patients with chronic pain who do not have comorbid depression. ${ }^{67}$ The risk of cardiovascular toxicity of TCAs must be considered in an elderly population. Although gabapentin has been widely employed in various types of chronic neuropathic pain, little evidence for efficacy in musculoskeletal pain is available. Other anticonvulsants such as carbamazepine, phenytoin, and sodium valproate are also used in the treatment of patients with neuropathic pain. ${ }^{68}$

The three step analgesic ladder, originally proposed for cancer pain relief by the World Health Organisation, ${ }^{69}$ is useful and now widely employed for all types of pain, including the chronic pain of musculoskeletal disease. 
The possibility of controlling otherwise intractable pain by the relatively brief application of a neurolytic agent or a local anaesthetic makes neural blockade an attractive approach in selected patients. Studies have concluded that treatment with nerve blocks alone is not very effective as a long term treatment for chronic pain..$^{70}$ Interpretation of these procedures has received much criticism as scientific studies validating their results are still wanting. ${ }^{71-73}$

\section{OPIOID INTERVENTION}

For carefully selected elderly patients, opioid analgesics may represent the optimal approaches to pain control and hopefully improved function. For significant pain inadequately relieved by acetaminophen or tramadol, opioids may pose less risk of major toxicity than NSAIDs as outlined above.

Since Portenoy and Foley's landmark paper in $1986,{ }^{74}$ multiple studies, many flawed, have suggested that long term opioid therapy (treatment for four or more years) effectively relieves pain in patients with non-malignant pain. Much less clear, however, is whether improvement in social or physical function-employment, recreational activities, even self care-accompanies pain reduction. Portenoy's retrospective review of 38 patients with non-malignant pain ( 14 with chronic back pain), most treated for more than four years with long term opioids, found that 24 patients noted partial or full relief of pain. However, no significant improvement in social function or employment was demonstrable. No toxicity was reported, though two of the patients with a prior history of substance abuse became "management problems". In a population of 112 patients treated with long term opioids for a mean of two years, Jamison et al reported that $83 \%$ of patients found the opioids "moderately beneficial" in relieving their pain ${ }^{75} ; 45 \%$ of these patients had chronic low back pain. In this retrospective analysis, no attempt to assess effect on functional status was possible. In a recent subsequent study, ${ }^{76}$ the same author compared sustained released morphine with naproxen and set dose oxycodone in 36 patients with chronic low back pain in a randomised, open trial. Though the opioid treated patients demonstrated superior pain relief and less emotional distress, no difference was found in activity level or hours of sleep. Similarly, Moulin et al, in a randomised, double blind crossover study of 46 patients, most of whom had regional myofascial pain syndromes, ${ }^{77}$ were treated with long acting morphine (MS Contin) and found significant improvement in pain control but no difference in physical or psychosocial function as assessed by the Sickness Impact Profile instrument. ${ }^{78}$ Conversely, in a study of 100 patients treated with long term opioid therapy, ${ }^{79}$ Zenz et al found that $79 \%$ of patients experienced good or partial pain relief and that significant improvement in the Karnofsky performance scale $^{80}$ and was seen in patients with at least a $50 \%$ improvement in pain level. The Karnofsky Performance Scale Index allows patients to be classified as to their functional impairment. This can be used to compare effectiveness of different therapies and to assess the prognosis in individual patients. The lower the Karnofsky score, the worse the survival for most serious illnesses.

\section{Addiction}

Fear of addiction has been a major barrier to long term opioid treatment in chronic non-malignant pain, particularly by physicians who may confuse physical dependence with addictive behaviour. Pseudoaddictive drug seeking by patients with poorly managed chronic pain may further discourage opioid treatment. A number of reports demonstrate minimal risk of addiction in patients treated with long term opioids who do not have a prior history of substance
Box 1: Suggested guidelines for long term opioid use

1. Patients considered for long term opioids should have a well defined structural source of pain.

2. Patients with non-specific musculoskeletal syndromes are poor candidates for long term opioids particularly if self assessed disability is inconsistent with underlying structural disease.

3. In many patients, a pre-therapy psychosocial assessment by an experienced pain psychologist or psychiatrist should be performed.

4. Patients with current or previous substance abuse should be considered for long term opioids only rarely and after careful psychological assessment and with meticulous follow up. In these patients, an opioid contract is mandatory.

5. In all patients with chronic non-malignant pain treated with opioids, regular assessment of efficacy of treatment should include pain and functional status. Functional measures may include pain disability index.

6. If treatment is ineffective as assessed by these parameters, it should be terminated.

abuse. ${ }^{75-77} 7981$ Moulin et al reviewed three studies including almost 25000 patients treated with long term opioids without a history of drug dependence and found only seven cases of iatrogenic addiction. ${ }^{77}$ Whether or not patients with a history of prior substance abuse but with an appropriate indication for long term opioids should ever be considered for such treatment is controversial. Dunbar and Katz retrospectively studied 20 patients with a history of chronic nonmalignant pain and substance abuse treated with chronic opioids for more than one year. ${ }^{82}$ Eleven of the 20 patients demonstrated no evidence of abuse. One of the factors associated with less risk of abuse was that these patients were more likely to have a stable family. In addition, they were active members of Alcoholics Anonymous, and had abused alcohol alone rather than multiple substances. Again, these studies did not specifically assess these issues in the older population.

\section{Tolerance}

The available clinical studies provide few data to answer the question of clinical tolerance. The retrospective analysis by Jamison et al of 112 patients found that 25\% of patients reported the opioid had not lost its ability to relieve the pain over time and $35 \%$ of patients reported no need to increase the dose of their medication. ${ }^{75}$ In general, our anecdotal clinical experience suggests that tolerance is not a significant clinical problem in older adults.

\section{Cognitive function}

Haythornthwaite et al studied 19 patients receiving long acting, oral opioid medications in comparison with 10 patients receiving usual care. ${ }^{83}$ Multiple tools assessing cognitive function were prospectively administered to both groups. No declines in cognitive function were associated with the long acting opioid medications and these patients actually showed significant improvement in measures of psychomotor speed and sustained attention. After reviewing the literature, Zacny concluded that morphine-like opioids do not appear to disrupt performance related to driving. ${ }^{84}$ These studies to date suggest that people taking opioids at a 
stabilised dose for medically approved reasons should be allowed to work. ${ }^{83}$ Further studies specifically in older patients who may have less "cognitive reserve" are required.

\section{Regulatory issues}

The roles of both health professionals and law enforcement personnel in maintaining the essential balance between patient care and diversion prevention is critical. Fears of regulatory sanctions, abuse, and side effects can lead to reluctance to prescribe opioids for non-cancer pain. Regulatory concerns are best addressed by careful, repeated assessment of the "four As": analgesia, activities of daily living, adverse effects, and aberrant behaviour. ${ }^{85}$ "Affect" could be a fifth addition to show the monitoring of the emotional side of pain. Failure to treat intractable pain is rapidly emerging as an important liability issue for physicians. ${ }^{81}$ The British Geriatrics Society compendium of good practice and the American Bar Association advocates a serious look at pain management and the rights of patients with pain.

\section{Side effects}

Opioids share a common mechanism of action, and common side effect profiles in the elderly. Their impact on the central nervous system, gastrointestinal function, and respiration may be clear, with less obvious effects on other systems including cardiovascular, urinary, skin, and others. Side effects may be related to a specific drug or combination of drugs, the total daily opioid dose, starting a drug or increasing the amount taken, drug by-products, and to the patient's age and concurrent medical condition. Recognising the side effects and treating them is important. Side effects can be avoided by using lower doses of the drug or administering less frequently (for example, eight hourly instead of four hourly). Because of age related declines in renal function, ${ }^{86}$ the elderly are theoretically more prone to adverse effects like agitation, myoclonus, and seizures than younger adults. Ultra-long acting opioids, such as methadone, should be used with extreme caution. Methadone is partly excreted unchanged in the urine and its half life outlasts its duration of analgesic action, making titration difficult. The drug can accumulate, and delayed toxicity can occur, especially in the elderly. ${ }^{87}$ Hence, initial and incremental doses of morphine and other opioid analgesics should generally be smaller for frail elderly patients because of age related pharmacodynamic and pharmacokinetic factors. ${ }^{88}$

Respiratory depression, sedation, constipation, nausea, vomiting, and itching are the other side effects of opioids encountered in practice. It is important to discuss these potential side effects with patients before and during the use of the medications. Health care professionals fear respiratory depression with the use of opioids. It is often a reason for under-dosing or limited use of opioids. ${ }^{89-91}$ Tolerance to the respiratory depressant effect of opioids occurs rapidly. Therefore, the risk is greater in the treatment of acute pain or with increased dose adjustments of opioids than with chronic treatments. ${ }^{92}$ All patients should be observed closely during times of peak analgesic blood concentrations and for respiratory depression. Most patients who have been receiving opioids will tolerate graduate increments in medication with little or no problem. However, because opioids can lead to hypotension and respiratory depression, caution is required in frail patients with haemodynamic instability or respiratory decompensation. If respiratory depression occurs, it should be treated cautiously with an antagonist such as naloxone. ${ }^{93}$

Sedation is a common complaint in opioid naive patients. This usually settles in 2-3 days. Sometimes a slight dose adjustment will decrease sedation but not increase pain. Switching to another analgesic with an equianalgesic dose is another option..$^{94}$ From a patient's standpoint, constipation is often the most troublesome consequence of opioid therapy. ${ }^{25} 95$ Do not wait until constipation occurs. Particularly in older patients using opioids regularly, prevention of constipation with stool softeners, adequate fluid intake, and non-bulk forming laxatives is advisable.

Equally nausea and vomiting are often transient and settle after 2-3 days. Systematic use of metoclopramide with opioid therapy for non-malignant pain decreases the risk of nausea and vomiting. ${ }^{97}$ If nausea and vomiting are persistent, switching to an equianalgesic dose of another opioid may relieve the symptoms. Allergic reactions to opioids are rare. A higher incidence of puritius occurs with intraspinal use of opioids. $^{9899}$ An assessment is necessary. Opioid induced histamine release from mast cells resulting in urticaria, pruritus, bronchospasm, and hypotension doesn't usually demonstrate a typical anaphylactic reaction cascade but nevertheless can in severe cases elicit the clinical picture of an anaphylactic shock. Opioid induced pruritus can be caused either centrally or peripherally by histamine liberation. The mechanism of centrally elicited pruritus is poorly understood. The opioid induced central pruritus can be reversed by naloxone and is probably caused by a change in neurotransmitter release in spinal and supraspinal centres. ${ }^{100}$

\section{CONCLUSION}

Musculoskeletal pain is common and under-treated in the elderly. Unfortunately, older patients are often excluded from studies assessing various medication effects in pain reduction. Often, an attempt is made in clinical trials to avoid the influences of other medical conditions or drug interactions with coadministered medications. As a result, most of the literature derived from studies employing pharmacological and non-pharmacological approaches has largely focused on diverse patient populations, not exclusively the elderly. Most new analgesics recently approved by the Food and Drug Administration have few data available on their use in patients over the age of 80 years or in those with multiple medical problems. Limited data are available to describe potential drug interactions.

As a result of physiological age related changes in drug metabolic pathways and comorbid disease, the elderly may be more sensitive to analgesic drug effect and or greater risk of toxicity. Despite potential risks, the need for improved pain management in the older population for greater function and quality of life mandates long term care. Controlled trials of opioid analgesia in this population to guide rational therapy are critically needed.

\section{Authors' affiliations}

V K Podichetty, Director, Research Studies and Education, Cleveland Clinic Florida Spine Institute, Weston, Florida

D J Mazanec, Chairman, Spine Center, Cleveland Clinic Foundation R S Biscup, Chairman, Cleveland Clinic Florida Spine Institute

\section{REFERENCES}

1 United Nations. World population prospects: the 1998 revision. New York: United Nations, 1999

2 US Bureau of the Census. Statistical abstract of the United States, 2001 Available at: http://www.census.gov/statab/www/brief.html (accessed 9 November 2002).

3 Furner SE, Brody JA, Jankowski LM. Epidemiology of the aging. In: Cassel CK, Cohen HJ, Larson EB, et al, eds. Geriatric medicine. 3rd Ed. New York: Springer-Verlag, 1990.

4 Taeuber CM, Rosenwaike I. A demographic portrait of Americas oldest old. In: Suzman RM, Willis DP, Manton KG, eds. The oldest old. New York: Oxford University Press, 1992.

5 United Nations. The ageing of the world's population. Population Division, Department of Economic and Social Affairs, United Nations Secretariat. Available at: http://www.un.org/esa/socdev/ageing/agewpop.html (accessed 7 February 2002). 
6 Guccione AA. Implications of an aging population for rehabilitation: demography, mortality, and morbidity in the elderly. In: Guccione AA, ed Geriatric physical therapy. St Louis, MO: Mosby Inc, 2000:3-16.

7 Blaum CS, Ofstedal MB, Liang J. Low cognitive performance, comorbid disease, and task-specific disability: findings from a nationally representative survey. J Gerontol A Biol Sci Med Sci 2002;57:M523-31.

8 Leveille SG, Ling S, Hochberg MC, et al. Widespread musculoskeletal pain and the progression of disability in older disabled women. Ann Intern Med $2001 \cdot 135: 1038-46$

9 Scudds RJ, Robertson McD. Empirical evidence of the association between the presence of musculoskeletal pain and physical disability in communitydwelling senior citizens. J Pain 1998;75:229-35.

10 Payne R. Practice guidelines for cancer pain treatment: issues pertinent to the revision of national guidelines. Oncology 1998;12:169-75.

11 McCaffery M. Pain control: barriers to the use of available information. Cancer 1992;70(suppl 5): 1438-49.

12 Bernabei R, Gambassi G, Lapane K, et al. Managing pain in elderly patients with cancer. JAMA 1998;279:1877-82.

13 Cooner E, Amorosi S. The study of pain and older Americans Study conducted for the National Council on the Aging. Study No 628200. New York: Louis Harris and Associates, 1997.

14 Ferrell BA, Ferrell BR, Rivera L. Pain in cognitively impaired nursing home patients. J Pain Symptom Manage 1995;10:591-8.

15 Lawrence RC, Helmick CG, Arnett FC, et al. Estimates of the prevelance of arthritis and selected musculoskeletal disorders in the United States. Arthritis Rheum 1998:41:778-99.

16 Davis MA, Ettinger WH, Neuhaus JM. Sex di9fferences in osteoarthritis of the knee (OAK). The role of obesity. Arthritis Rheum 1986;29:S16.

17 Felson DT. The epidemiology of knee osteoarthirits: results from Framingham Study. Seminars Arthritis Rheum 1990;20:42-50.

18 Solomon L. Clinical features of osteoarthritis. In: Kelley WN, Ruddy S Harris EDJ, et al, eds. Textbook of rheumatology. Vol 2. 5th Ed. Philadelphia: WB Saunders, 1997:1383-408

19 Weinstein JN, Birkmeyer JD. The Dartmouth atlas of musculoskeletal health care. Chicago: AHA Press, 2000:138-9.

20 Chudler EH, Dong WK. The role of the basal ganglia in nociception and pain. Pain 1995;60:3-38.

21 Hochberg MC, Altman RD, Brandt KD, et al. Guidelines for the medical management of osteoarthritis, part II. Osteoarthritis of the knee. Arthritis Rheum 1995;38:1541-6.

22 Crook J, Rideout E, Browne G. The prevalence of pain complaints among a general population. Pain 1984;18:299-314.

23 Magni G, Marchetti M, Moreschi C, et al. Chronic musculoskeletal pain and depressive symptoms in the National Health and Nutrition Examination I. Epidemiologic follow-up study. Pain 1993;53:163-8.

24 Ferrell BA, Ferrell BR, Osterweil D. Pain in the nursing home. J Am Geriatr Soc 1990;38:409-14.

25 American Geriatrics Society. AGS Panel on Chronic Pain in Older Persons. The management of chronic pain in older persons. J Am Geriatr Soc 1998:46:635-51.

26 Ferrell BA. Pain management in elderly people. J Am Geriatr Soc 1991;39:64-73

27 Melding PS. Is there such a thing as geriatric pain? Pain 1991;46:119-21.

28 Mazanec DJ. Diagnosis and management of low back pain in older adults. Clinical Geriatrics 2000;8:63-71.

29 Roy R, Thomas M. A survey of chronic pain in an elderly population. Can Fam Physician 1986;32:513-16.

30 Roy R. A psychosocial perspective on chronic pain and depression in the elderly. Social Work in Health Care 1986;12:27-36.

31 Magni G, Fabrizio S, De Leo D. Pain as a symptom in elderly depressed patients. Eur Arch Psychiatr Neurol Sci 1985;235:143-5.

32 Magni G, Caldieron C, Rigatti-Luchini S, et al. Chronic musculoskeletal pain and depressive symptoms in the general population. An analysis of the 1st National Health and Nutrition Examination Survey data. Pain 1990:43:299-307.

33 Parmelee PA, Katz IR, Lawton MP. The relation of pain to depression among institutionalized aged. J Gerontol 1991;46:15-21.

34 Ingram SS, Seo PH, Martell RE, et al. Comprehensive assessment of the elderly cancer patient: the feasibility of self-report methodology. J Clin Oncol 2002;20:770-5

35 Kane RL, Ouslander JG, Abrass IB. Essentials of clinical geriatrics. 2nd Ed. New York: McGraw-Hill, 1989.

36 Parmelee PA, Smith B, Katz IR. Pain complaints and cognitive status among elderly institution residents. J Am Geriatr Soc 1993;41:517-22.

37 American Geriatrics Society. AGS Panel on Persistent Pain in Older Persons. The management of persistent pain in older persons. J Am Geriatr Soc 2002;50: 1-20.

38 Ferrell BA, Ferrell BR. Principles of pain management in older people. Compr Ther 1991; 17:53-8.

39 Ferrell BR. Patient education and nondrug interventions. In: Ferrell BR, Ferrell BA, eds. Pain in the elderly. Seattle: IASP Press, 1996:35-44.

40 Penninx BW, Messier SP, Rejeski W, et al. Physical exercise and the prevention of disability in activities of daily living in older persons with osteoarthritis. Arch Intern Med 2001;161:2309-16.

41 Messier SP, Glasser JL, Ettinger WH Jr, et al. Declines in strength and balance in older adults with chronic knee pain: a 30-month longitudinal, observational study. Arthritis Rheum 2002;47:141-8.

42 Mangione KK, McCully K, Gloviak A, et al. The effects of high-intensity and low-intensity cycle ergometry in older adults with knee osteoarthritis. J Gerontol A Biol Sci Med Sci 1999;54:M184-90.
43 Thomas KS, Muir KR, Doherty M, et al. Home based exercise programme for knee pain and knee osteoarthritis: randomised controlled trial. BMJ 2002;325:752.

44 Deyo RA, Walsh NE, Martin DC, et al. A controlled trial of transcutaneous electrical nerve stimulation (TENS) and exercise for chronic low back pain. N Engl J Med 1990;322:1627-34

45 Milne S, Welch V, Brosseau L, et al. Transcutaneous electrical nerve stimulation (TENS) for chronic low back pain. Cochrane Database Systematic Reviews 2001 ;:CD003008.

46 Brosseau L, Milne S, Robinson V, et al. Efficacy of the transcutaneous electrical nerve stimulation for the treatment of chronic low back pain: a meta analysis. Spine 2002;27:596-603.

47 Deal CL, Moskowitz RW. Nutraceuticals as therapeutic agents in osteoarthritis. The role of glucosamine, chondroitin sulfate, and collagen hydroslyate. Rheum Dis Clin North Am 1999;25:379-95.

48 McAlindon TE, LaValley MP, Gulin JP, et al. Glucosamine and chondroitin for treatment of osteoarthritis. A systematic quality assessment and metaanalysis. JAMA 2000;283:1469-75.

49 American Society of Anesthesiologists (ASA) - practice guidelines for chronic pain management. Anesthesiology 1997;86:995-1004

50 Ward SE, Goldberg N, Miller-McCauley V, et al. Patient-related barriers to management of cancer pain. Pain 1993:52:319-24.

51 Rimer B, Levy MH, Keintz MK, et al. Enhancing cancer pain control regimens through patient education. Patient Education and Counseling 1987; 10:267-77

52 Hochberg MC, Altman RD, Brandt KD, et al. Guidelines for the medical management of osteoarthritis. Part I. Osteoarthritis of the hip. Arthritis Rheum 1995:38:1535-40.

53 Phillips AC, Polisson RP, Simon LS. NSAIDs and the elderly. Toxicity and economic implications. Drugs Aging 1997;10:119-30.

54 Dalgin P, TPS-OA Study Group. Comparison of tramadol and ibuprofen for the chronic pain of osteoarthritis. Arthritis Rheum 1997:40(suppl 9):S86

55 Schnitzer TJ. Update of ACR guidelines for osteoarthritis; role of the coxibs. J Pain Symptom Manage 2002;23(suppl 4):S24-30.

56 American College of Rheumatology, Subcommittee on Osteoarthritis Guidelines. Recommendations for the medical management of osteoarthritis of the hip and knee: 2000 update. Arthritis Rheum 2000;43:1905-15.

57 Singh G. Recent considerations in nonsteroidal anti-inflammatory drug gastropathy. Am J Med 1998;105(suppl 1B):31S-8S.

58 Schnitzer TJ. Managing chronic pain with tramadol in elderly patients. Clinical Geriatrics 1999:7:35-45.

59 Bamigbade TA, Davidson C, Langford RM, et al. Actions of tramadol, its enantiomers and principal metabolite, O-desmethyltramadol, on serotonin (5-HT) efflux and uptake in the rat dorsal raphe nucleus. Br J Anaesth 1997:79:352-6

60 Raffa RB, Friderichs E. The basic science aspect of tramadol hydrochloride. Pain Reviews 1996;3:249-71.

61 Wilder-Smith CH, Hill L, Osler W, et al. Effect of tramadol and morphine on pain and gastrointestinal motor function in patients with chronic pancreatitis. Dig Dis Sci 1999:44:1107-16.

62 Preston KL, Jasinski DR, Testa M. Abuse potential and pharmacological comparison of tramadol and morphine. Drug Alcohol Depend 1991;27:7-17.

63 McQuay HJ, Tramèr M, Nye BA, et al. A systematic review of antidepressants in neuropathic pain. Pain 1996:68:217-27.

64 Onghena P, Van Houdenhove B. Antidepressant-induced analgesia in chronic non-malignant pain: a meta-analysis of 39 placebo-controlled studies. Pain 1992;49:205-19.

65 Volmink J, Lancaster T, Gray S, et al. Treatments for postherpetic neuralgia: A systematic review of randomized controlled trials. Fam Pract 1996;13:84-91

66 Raphael J, Leo RJ, Singh A. Pain management in the elderly: use of psychopharmacologic agents. Annals of Long-Term Care: Clinical Care and Aging 2002;10:37-45.

67 Feinmann C. Pain relief by antidepressants: possible modes of action. Pain 1985;23:1-8

68 Galer BS. Neuropathic pain of peripheral origin: advances in pharmacologic treatment. Neurology 1995:4:S17-25.

69 World Health Organisation. WHO guidelines: cancer pain relief. 2nd Ed. Geneva: WHO, 1996

70 Johansson A, Sjolund B. Nerve blocks with local anesthetics and corticosteroids in chronic pain: a clinical follow-up study. J Pain Symptom Manage 1996;11:181-7

71 Boas RA, Hatangdi BS, Richards EG. Lumbar sympathectomy: a percutaneous chemical technique. Adv Pain Res Ther 1976;1:685-9.

72 Dory MA. Arthrography of the lumbar facet joints. Radiology $1981 ; 140: 23-7$

73 Jackson RP, Jacobs RR, Montsano PX. Facet joint injection in low back pain: Prospective statistical study. Spine 1988;13:66-71.

74 Portenoy RK, Foley KM. Chronic use of opioid analgesics in non-malignant pain: report of 38 cases. Pain 1986;25:171-86.

75 Jamison RN, Anderson KO, Peeters-Asdourian C, et al. Survery of opioid use in chronic nonmalignant pain patients. Reg Anesth 1994;19:225-30.

76 Jamison RN, Raymond SA, Slawsby EA, et al. Opioid therapy for chronic noncancer back pain. A randomized prospective study. Spine 1998:23:2591-600.

77 Moulin DE, lezzi A, Amireh R, et al. Randomized trial of oral morphine for chronic non-cancer pain. Lancet 1996;347:143-7.

78 Bergner M, Bobbitt RA, Carter WB, et al. The sickness impact profile: development and final revision of a health status measure. Med Care $1981 ; 19: 787-805$. 
79 Zenz M, Strumpf M, Tryba M. Long-term oral opioid therapy in patients with chronic nonmalignant pain. J Pain Symptom Manage 1992;7:69-77.

80 Karnofsky DA, Burchenal JH. The clinical evaluation of chemotherapeutic agents in cancer. In: MacLeod CM, ed. Evaluation of chemotherapeutic agents. New York: Columbia University Press, 1949:196.

81 Dunegan L. The ethics of pain management. Annals of Long-Term Care: Clinical Care and Aging 2000;8:23-26.

82 Dunbar SA, Katz NP. Chronic opioid therapy for nonmalignant pain in patients with a history of substance abuse: report of 20 cases. J Pain Symptom Manage 1996;11:163-71.

83 Haythornthwaite JA, Menefee LA, Quatrano-Piacentini AL, et al. Outcome of chronic opioid therapy for non-cancer pain. J Pain Symptom Manage 1998; 15:185-94.

84 Zacny JP. Should people taking opioids for medical reasons be allowed to work and drive? (Editorial). Addiction 1996:91:1581-4.

85 Passik SD, Weinreb HJ. Managing chronic nonmalignant pain: overcoming obstacles to the use of opioids. Advances in Therapy 2000;17:71-83.

86 Rowe JW, Andres R, Tobin JD, et al. The effect of age in creatinine clearance in man: a cross sectional and longitudinal study. J Gerontol 1976;31:155-63.

87 Ettinger DS, Vitale PJ, Trump DL. Important clinical pharmacological considerations in the use of methadone in cancer patients. Cancer Treat Rep 1979:63:457-9

88 Ahronheim JC. Handbook of prescribing medications for geriatric patients Boston, MA: Little Brown, 1992.

89 Marks RM, Sachar EJ. Undertreatment of medical inpatients with narcotic analgesics. Ann Intern Med 1973;78:173-81.

90 Weissman DE. Doctors, opioids, and the law: the effect of controlled substances regulations on cancer pain management. Semin Oncol 1993;20(2 suppl 1):53-8.

91 Bernabei R, Gambassi G, Lapane K, et al. Management of pain in elderly patients with cancer. SAGE Study Group. Systematic assessment of geriatric drug use via epidemiology. JAMA 1998;279:1877-82.

92 Jurna I, Grossman W. The effects of morphine on mammalian nerve fibres. Eur J Pharmacol 1977:44:339-48.

93 Borgbjerg FM, Nielsen K, Franks J. Experimental pain stimulates respiration and attenuates morphine-induced respiratory depression: a controlled study in human volunteers. Pain 1996;64:123-8.

94 Joranson DE, Carrow GM, Ryan KM, et al. Pain management and prescription monitoring. J Pain Symptom Manage 2002;23:231-8.
95 Jacox A, Carr DB, Payne R. New clinical-practice guidelines for the management of pain in patients with cancer. N Engl J Med 1994;330:651-5

96 Ellison NM. Opioid analgesics for cancer pain: toxicities and their treatments. In: Patt RB, ed. Cancer pain. Philadelphia: JB Lippincott, 1993.

97 Scotto di Fazano C, Vergne P, Grilo RM, et al. Preventive therapy for nausea and vomiting in patients on opioid therapy for non-malignant pain in rheumatology. Therapie 2002;57:446-9.

98 Vrchoticky T. Naloxone for the treatment of narcotic induced pruritis. The Journal of Pediatric Pharmacy Practice 2000:5:92-6.

99 Du Pen SL, Peterson DG, Williams A, et al. Infection during chronic epidural catheterization: diagnosis and treatment. Anesthesiology 1990;73:905-9.

100 Scott PV, Fischer HBJ. Intraspinal opiates and itching: a new relief? BMJ 1982;284:1015-16.

101 Wolfe MM, Lichtenstein DR, Singh G. Medical progress: gastrointestinal toxicity of nonsteroidal anti-inflammatory drugs. N Engl J Med 1999;340: 1888-99.

102 Hernandez-Diaz S, Garcia-Rodriguez LA. Association between nonsteroidal anti-inflammatory drugs and upper gastrointestinal tract bleeding/ performation. Arch Intern Med 2000;160:2093-9.

103 Mukheriee D, Nissen SE, Topol EJ. Risk of cardiovascular events associated with selective COX-2 inhibitors. JAMA 2001;286:954-9.

104 Page J, Henry D. Consumption of NSAIDs and the development of congestive heart failure in elderly patients: an underrecognized public health problem. Arch Intern Med 2000;160:777-84.

105 Feenstra J, Heerdink ER, Grobbee DE, et al. Association of nonsteroidal antiinflammatory drugs with first occurrence of heart failure and with relapsing heart failure: The Rotterdam Study. Arch Intern Med 2002;162:265-70.

106 Swan SK, Rudy DW, Lasseter KC, et al. Effect of cyclooxygenase-2 inhibition on renal function in elderly persons receiving a low-salt diet. Ann Intern Med 2000; 133:1-9.

107 Mayer DJ. Acupuncture: an evidence based review of the clinical literature. Annu Rev Med 2000;51:49-63.

108 Lao L, Ezzo J, Berman B, et al. Assessing clinical efficacy of acupuncture: considerations for designing future acupuncture trials. In: Stux $G$, Hammerschlag R, eds. Scientific basis of acupuncture. Berlin: SpringerVerlag, 2000:187-210.

109 Ezzo J, Hadhazy V, Birch S, et al. Acupuncture for osteoarthritis of the knee: a systematic review. Arthritis Rheum 2001;44:819-25.

110 Leffler CT, Philippi AF, Leffler SG, et al. Glucosamine, chondroitin, and manganese ascorbate for degenerative joint disease of the knee or low back: a randomized, double-blind, placebo-controlled pilot study. Mil Med 1999; 164:85-91.

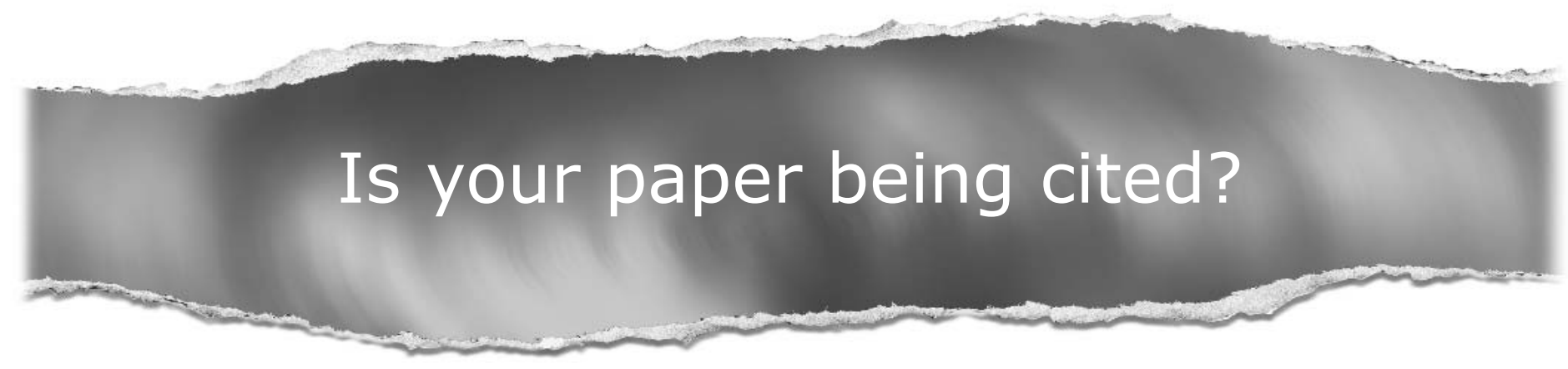

\section{CiteTrack service}

CiteTrack will alert you by email whenever new content in Postgraduate Medical Journal or a participating journal is published

that matches criteria you want to track

Topics: Tell CiteTrack which words or subjects to watch for in new content

Authors: Be alerted whenever key authors you are following publish a new paper

Articles: Know whenever a paper of interest to you is referenced by another paper 